ISSN 2466-2232

Online ISSN 2466-2100

\title{
$\mathrm{DC}-\mathrm{AC}$ 펄스 탄뎀 $\mathrm{GMA}$ 용접에서 공정변수에 따른 스패터 발생 거동에 대한 연구
}

\author{
강 상 훈,*** 방 희 선** 김 철 희 ${ }^{*+}$ \\ *한국생산기술연구원 용접접합그룹 \\ **조선대학교 용접접합과학공학과
}

\section{Spatter Generation During Constant Voltage DC-AC Pulse Tandem Gas Metal Arc Welding Process}

\author{
Sanghoon Kang*,**, Hee-seon Bang**, and Cheolhee Kim*, $\dagger$ \\ *Joining R\&D Group, KITECH, Incheon, 21999, Korea \\ **Welding and Joining Science Engineering, Chosun University, Kwangju, 61452, Korea
}

†Corresponding author : chkim@kitech.re.kr

(Received June 4, 2018 ; Revised June 12, 2018 ; Accepted June 19, 2018)

\begin{abstract}
High deposition is required to improve welding efficiency in the thick plate welding. Tandem gas metal $\operatorname{arc}($ GMA) welding has been introduced for high deposition and synchronized DC pulse welding system is usually employed to avoid the electro-magnetic interruption between two adjacent arcs. In this study, constant voltage DC welding for leading arc and AC pulse welding for trailing arc were combined for tandem welding without any synchronization for cost effectiveness. Spatter generation and droplet transfer were observed for various inter-wire distances, leading currents and trailing currents. The spatters were mainly generated from the droplets on the leading electrode. Two mechanisms for spatter generation were explained from high speed images. The droplet was deflected by the trailing arc and could not be transferred into the weld pool. The instant short circuiting of streaming mode droplet was another cause of the spatter generation. Adequate inter-wire distances and current ranges for leading and trailing electrodes were suggested to suppress spatter generation.
\end{abstract}

Key Words : Gas metal arc welding, Tandem welding, Constant voltage DC welding, AC pulse welding, High deposition

\section{1. 서 론}

아크 용접공정에서 생산성과 용착량을 높이기 위한 방법으로 하나로 2 개 이상의 와이어를 이용하는 탄뎀 (tandem) 용접공정이 적용되고 있다 ${ }^{1-5)}$. 이러한 탄뎀 아크용접에서 두 개의 전극이 인접하여 아크를 발생시키 기 때문에 아크 간섭이 발생하게 되어 용접성에 영향을 미친다. 선행연구에서 탄뎀 가스메탈 아크용접(GMAW) 를 적용할 경우 정전압 $\mathrm{DC}$ 용접전원을 동기화없이 2대 적용하거나 $\mathrm{DC}$ 펄스용접전원을 동기화하여 적용하였다
6-8). 비동기형 용접전원의 경우 아크 간섭에 의해 용접 조건의 선정이 어렵고, 동기형 펄스용접전원의 경우 시 스템 가격이 고가라는 단점이 있다.

$\mathrm{AC}$ 펄스용접는 정극성 구간에서 와이어 용융속도가 더 빠르기 때문에 기존 $\mathrm{DC}$ 펄스용접에 비해 같은 전류 에서 더 많은 용착량을 달성할 수 있다 ${ }^{9,10)}$. 서브머지드 아크용접에서는 $\mathrm{DC}$ 용접전원과 $\mathrm{AC}$ 용접전원을 탄뎀으 로 이용하는 방식이 일반적이나 ${ }^{11)}$, 아직 GMAW에서는 $\mathrm{AC}$ 펄스용접을 이용한 탄뎀시스템에 대한 연구가 이루 어지지 않았다.

따라서 본 연구에서는 정전압 $\mathrm{DC}$ 용접전원과 $\mathrm{AC}$ 펄 
스용접전원을 이용하여 탄뎀 $\mathrm{GMAW}$ 를 구성하고 공정 특성을 분석하고자 한다.

\section{2. 실험장치 및 방법}

본 실험을 위해 사용된 모재는 $12 \mathrm{~mm}$ 두께의 연강 을 사용였고, 용접와이어는 $1.2 \mathrm{~mm}$ 직경의 솔리드와 이어(AWS A5.18 ER70S-3)를 사용하였다. 선행 용 접전원은 $\mathrm{DC}$ 펄스용접전원인 OTC Welbee P500L을 정전압모드로 사용하였으며, 후행 용접전원은 $\mathrm{OTC}$ $\mathrm{DW} 300$ 을 $\mathrm{AC}$ 펄스모드로 사용하였다. 보호가스는 선행 용접의 경우 $\mathrm{Ar} 80 \%-\mathrm{CO}_{2} 20 \%$ 혼합가스를 $25 \mathrm{~L} / \mathrm{min}$ 으로 공급하였으며, 후행용접의 경우 $\mathrm{Ar} 90 \%-\mathrm{CO}_{2} 10 \%$ 혼합가스를 $25 \mathrm{~L} / \mathrm{min}$ 으로 공급하였다.

용접성은 비드(Bead-On-Plate) 용접을 통해 평가 하였으며, 토치의 구성은 Fig. 1과 같다. 선행과 후행 토치는 수직에 대해 각각 $1^{\circ}$ 의 각도를 가지고 고정되 었다. 와이어간 거리는 8- $18 \mathrm{~mm}$ 로 가변하였으며, 선행토치와 후행토치의 전류는 각각 $100-350 \mathrm{~A}$, 100 - $330 \mathrm{~A}$ 로 가변하였다. 선행토치의 경우 정전압 $\mathrm{DC}$ 용접를 수행하였는데 각 전류에 대해 용접전원에서 제안한 전압값을 사용하였으며, 그 범위는 $26-29 \mathrm{~V}$ 이다. 후행 토치의 경우 평균 전류에 따라 $\mathrm{EN}$ 비 $30 \%$ 에 용접전원내에 설정된 $\mathrm{AC}$ 펄스 시너직을 사용하였 다. 실험변수는 Table 1 에 정리하였다.

위의 실험조건으로 아크 간섭, 용적 이행과 용융풀 거

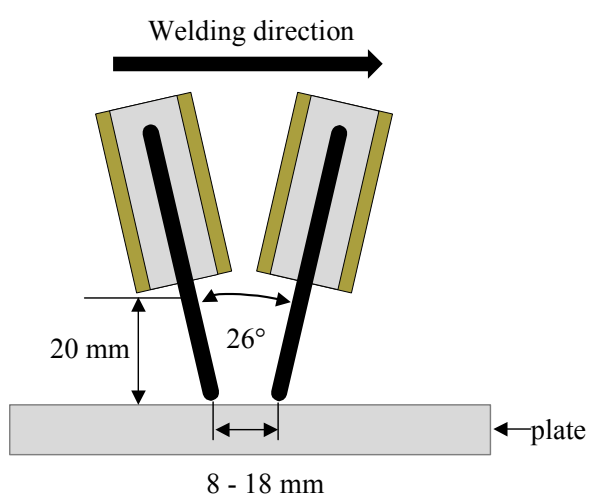

Fig. 1 Schematic diagram of experimental setup

Table 1 Welding parameters used in the experiments

\begin{tabular}{|l|c|}
\hline Welding current (leading arc) [A] & $250-350$ \\
\hline Welding voltage (leading arc) [V] & $26-39$ \\
\hline Average welding current (trailing arc) [A] & $100-300$ \\
\hline Average welding voltage (trailing arc) [A] & $18.5-26$ \\
\hline Welding speed [m/min] & 1.6 \\
\hline Inter-wire distance [mm] & $8-18$ \\
\hline Contact tip-to-workpiece distance, $[\mathrm{mm}]$ & 20 \\
\hline
\end{tabular}

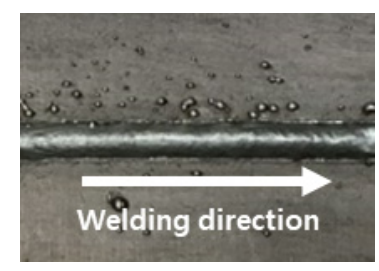

(a)

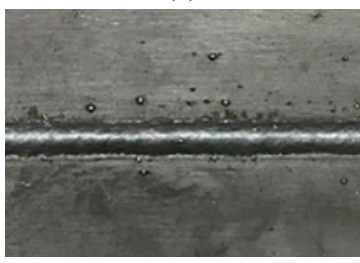

(c)

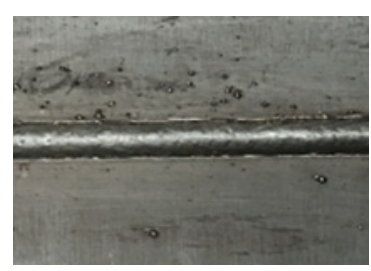

(b)

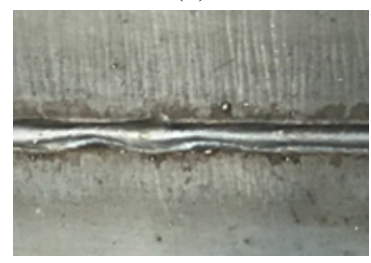

(d)
Fig. 2 Comparison of bead appearance according to the inter-wire distances. (a) $8 \mathrm{~mm}$; (b) $12 \mathrm{~mm}$; (c) 15 $\mathrm{mm}$; (d) $18 \mathrm{~mm}$. Specimens were fabricated under 250 A leading current, 250 A trailing current, and welding speed of $1.6 \mathrm{~m} / \mathrm{min}$

동을 관찰하기 위하여 FASTCAM사의 Mini UX50의 초고속 카메라를 사용하여 초당 5000프레임으로 고속 촬영을 하였다. 용접전류, 전압파형은 $50 \mathrm{kHz}$ 로 샘플 링하여 15 초간 측정을 하였다. 용접 후 소재에 부착된 스패터량과 비드 외관을 육안으로 관찰하였다.

\section{3. 실험결과 및 고찰}

\section{1 와이어간 거리에 따른 영향}

와이어간 거리에 따른 아크 간섭 현상과 이에 따른 용접성을 평가하기 위하여 선행 전류와 후행전류를 모 두 $250 \mathrm{~A}$ 로 고정을 하고 와이어간 거리를 8-18 mm 로 가변하면서 용접을 수행하였다. 와이어간 거리가 $8 \mathrm{~mm}$ 일 때는 아크 간섭으로 인해 시편 표면에 가장 많은 스 패터가 부착되었으며, 와이어간 거리가 $18 \mathrm{~mm}$ 일 경우 불균일한 비드가 형성됨이 관찰되었다. 표면 부착 스패 터 및 비드형상의 안정성 관점에서는 와이어간 거리가 $12 \mathrm{~mm}$ 인 경우가 가장 좋은 것으로 판단된다.

와이어간 거리에 따른 아크 및 용융풀의 거동은 Fig. 3 과 같다. 후행 $\mathrm{AC}$ 용접에서 역극성을 가질 경우 선행 $\mathrm{DC}$ 아크와 인력이 작용한다. Fig. $3 \mathrm{a}$ 의 (1)에서 가장 높은 역극성 전류를 가지므로 와이어간 거리가 $8 \mathrm{~mm}$ 일 때에는 선행 전극에서 분리된 용적이 후행 전극쪽으 로 날리면서 스패터가 발생하는 것이 관찰된다. 후행 $\mathrm{AC}$ 용접에서 (3), (4)와 같이 정극성을 가지는 경우에는 척력이 발생하고 역극성에 비해 전류값이 낮기 때문에 아크의 휨은 크지 않다. 고속촬영 결과에서도 와이어간 거리가 길어지면 선행 전극에서 분리된 용적이 날림이 줄 


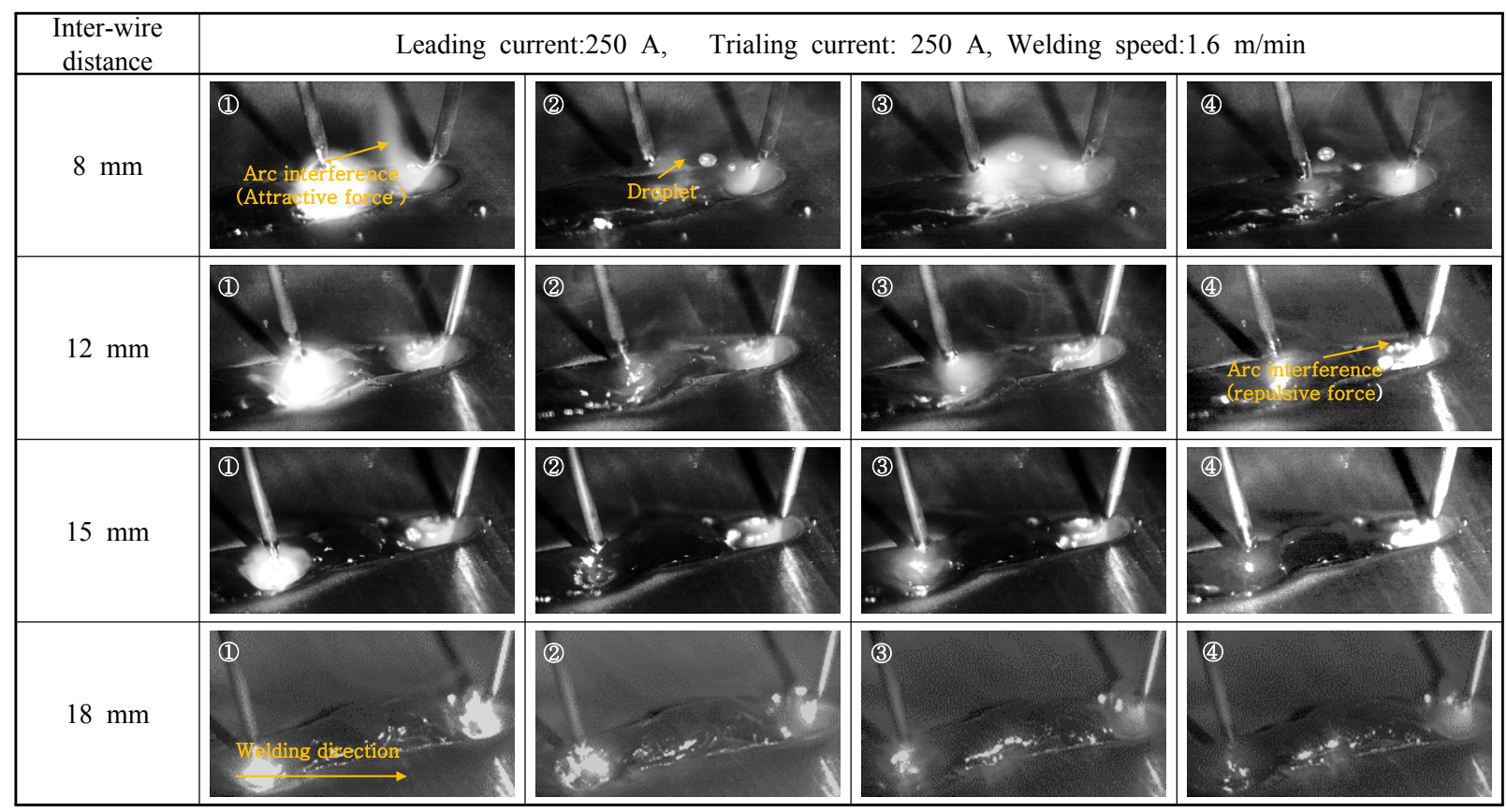

(a)

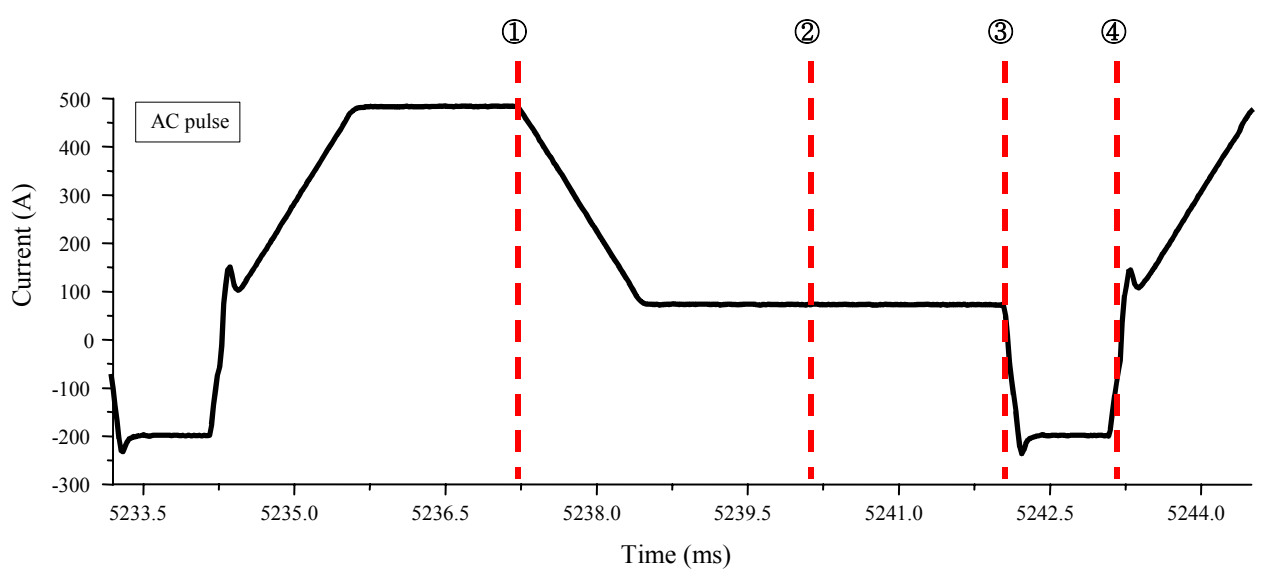

(b)

Fig. 3 Arc interference and droplet phenomena with various inter-wire distances, (a) images of high speed camera and (b) an AC pulse waveform including measured points of high speed camera images (inter-wire distance of $12 \mathrm{~mm}$ )

어드는 것을 확인할 수 있다. 와이어간 거리가 $18 \mathrm{~mm}$ 인 경우에는 하나의 용융풀을 형성하기는 하나 선행아 크와 후행아크 사이에 용융풀이 압력으로 높아지는 상 이 관찰되고 Fig. $2 \mathrm{~d}$ 와 같은 불균일한 비드 형성의 원 인으로 판단된다. 와이어 간 거리가 $18 \mathrm{~mm}$ 이상부터는 Fig. 2 d에서 보이는 것과 같이 용접비드가 불규칙한 폭이 발생하는 것을 볼 수 있다. 용융풀의 높이가 높아 질 경우 용융 풀과 후행 와이어와 순간적인 단락을 일 으킬 수 있다. 이러한 결과는 Ueyama의 연구와 유사 한 경향을 보인다 ${ }^{6)}$.

Fig. 3에서 선행 와이어의 용적이행거동을 보면 프로 젝티드 이행과 스트리밍 이행이 발생하였는데 와이어간 거리가 가까울 경우에는 스트리밍 이행이 관찰되고, 와
이어간 거리가 멀 경우에는 프로젝티드 이행이 관찰된 다. 이는 후행 아크로부터 입열이 선행 와이어에 영향 을 주어 이행 모드가 바뀌는 것으로 보이는데 스트리밍 이행의 경우에는 아크 간섭에 의해 와이어 끝단에 매달 린 용적이 영향을 더 많이 받아 스패터 발생의 원인이 된다.

본 실험에서 스패터 발생에는 2가지 모드가 존재한 다. 첫 번째로 Fig. 4c, $4 \mathrm{~d}$ 를 보게 되면 후행 와이어 의 전류가 역극성일 때 선행 와이어의 전류와 같은 극 성이기 때문에 서로 인력이 작용하게 된다. 이러한 인 력에 인해 선행 와이어의 용적이 용융 풀로 이행되지 않고 후행 아크 쪽으로 편향되면서 용적의 날림이 발생 한다. 후행 아크가 역극성에서 정극성으로 변하게 되면 


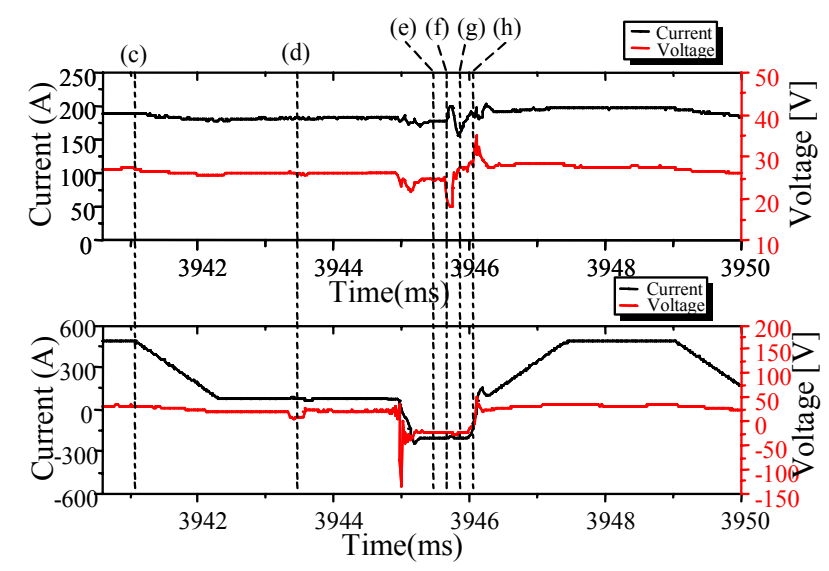

(a)

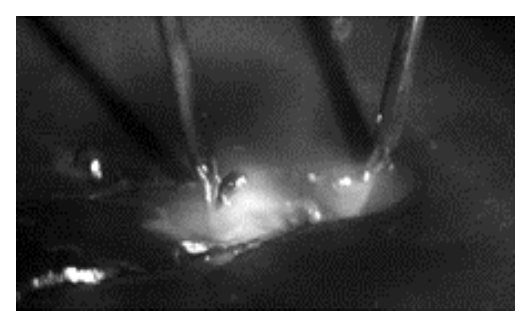

(c)

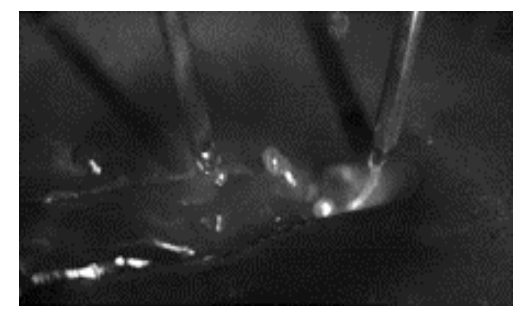

(f)

(d)

(g)

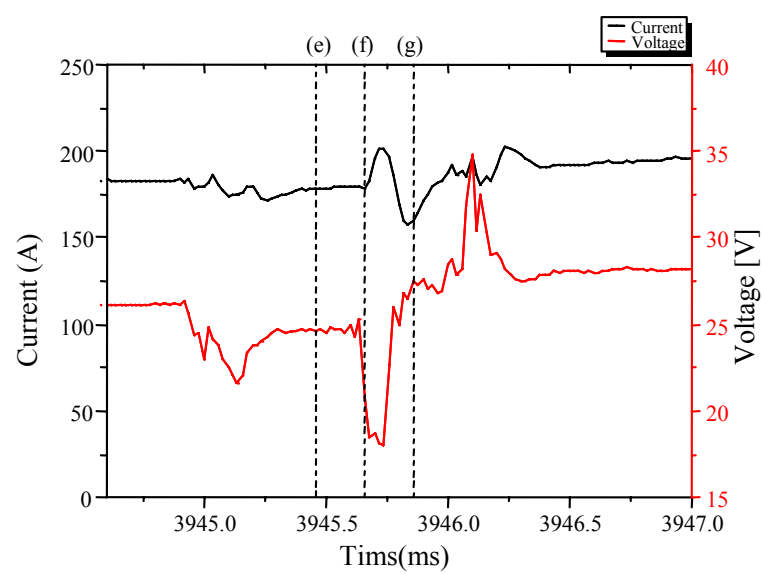

(b)
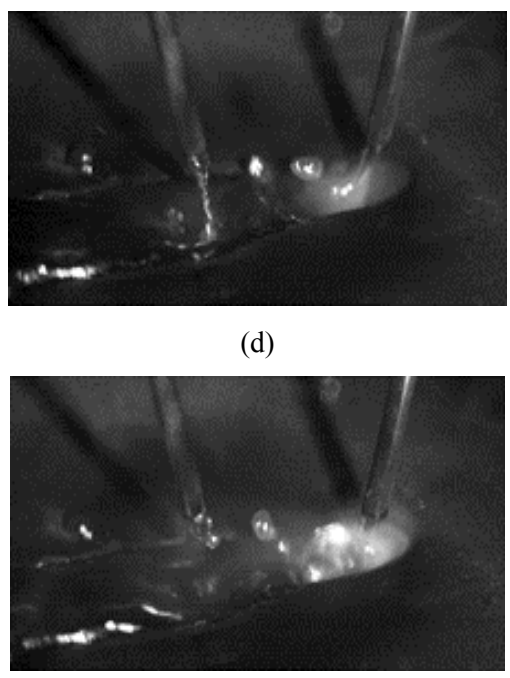

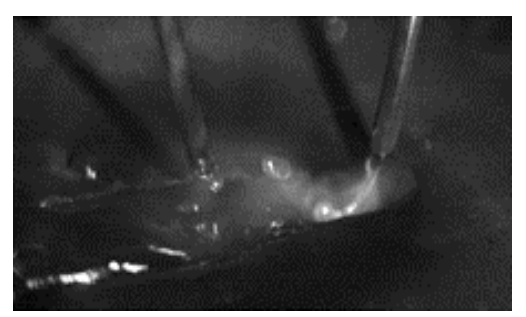

(e)

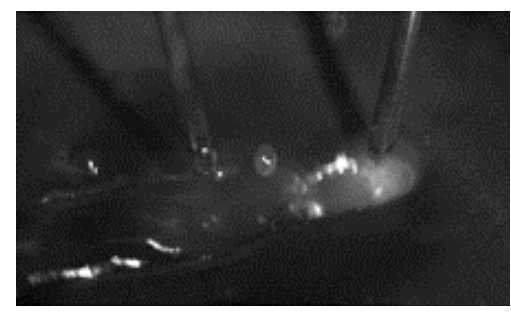

(h)

Fig. 4 Measured current-voltage waveform and high-speed camera images during the constant voltage DC-AC pulse tandem GMA welding. (a) current and voltage waveforms during one cycle, (b) high magnification of leading arc waveforms, (c)-(h) high speed camera images with respect to time (inter-wire distance $8 \mathrm{~mm}$ )

후행아크 방향을 향하던 선행 아크와 용적은 Fig. $4 \mathrm{e}$ 와 같이 다시 아래 방향을 향하게 되고 이 때 Fig. $4 \mathrm{f}$ 에서 보는 것과 같이 아크가 약해지면서 와이어 끝단에 매달린 용적과 용융풀이 순간적으로 접촉되어 단락 및 스패터가 발생하게 된다(Fig. $4 \mathrm{~g}$ 와 $4 \mathrm{~h}$ ). 스패터 발생 전에 선행 전극의 전압이 순간적으로 낮아지며 단락되 어 전류가 상승함은 Fig. $4 \mathrm{a}$ 와 $4 \mathrm{~b}$ 의 전류/전압 파형에 서도 볼 수 있다.

\section{2 선행 전류의 영향}

선행와이어의 전류에 따른 용접특성을 평가하기 위해 선행 전류값을 250 - 350 A로 가변하였다. 후행 전류 는 선행 전류값의 $31-50 \%$ 일 때 안정적 용접이 가 능하다고 알려져 있는데 ${ }^{6)}$, 본 연구에서는 선행전류값의 $40 \%$ 로 설정하여 $100-140$ A로 가변하였다. Fig. 5
는 선행전류에 따른 비드 외관인데 선행 전류가 높을수 록 스패터가 많이 발생하여 시편의 표면에 부착됨이 확 인된다. 이는 아크 간섭과 선행 전극에서의 스트리밍 이 행모드가 주된 원인이다.

본 실험에서는 선행전류가 높을 경우 후행전류도 같 이 높게 설정이 되고 Fig. 6의 고속촬영결과에서 확인 할 수 있는 것처럼 아크간의 전자기력이 커지기 때문에 아크의 간섭이 심하다. 또한 전류가 높을 경우 용적의 이행이 프로젝티드 이행에서 스트리밍 이행으로 전환되 므로 스패터 발생량 증가의 원인이 된다.

선행전류가 350 A일 경우(Fig. 6a)에는 주로 스트리 밍 이행이 관찰되지만 선행전류가 300 A일 경우(Fig. $6 \mathrm{~b})$ 에는 스트리밍과 프로젝트 이행이 교차하여 발생한 다. 선행전류가 $250 \mathrm{~A}$ 인 경우에는 프로젝트 이행이 발 생하였으며, 아크 간섭이 가장 작기 때문에 스패터가 상 


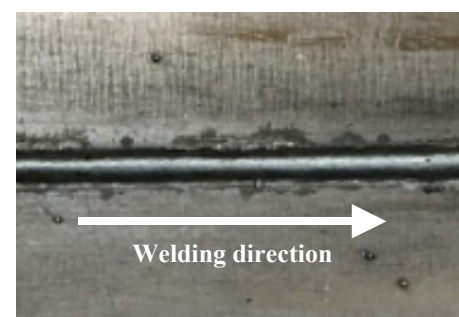

(a)

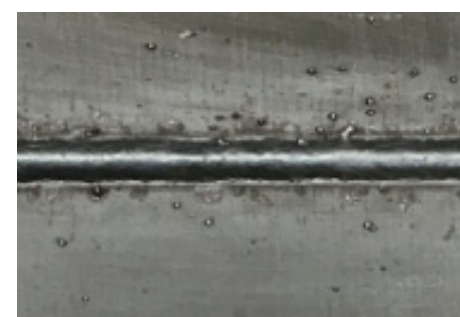

(b)

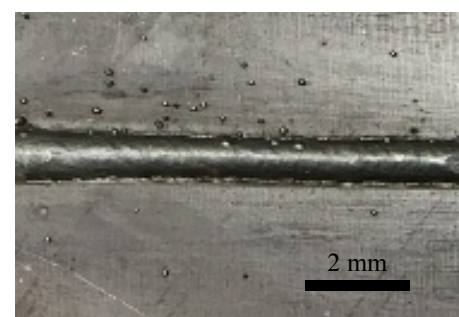

(c)

Fig. 5 Comparison of bead appearance according to the leading current: (a) 350 A, (b) 300 A, (c) 250 A. Specimens were fabricated under inter-wire distance of $12 \mathrm{~mm}$ and welding speed of $1.6 \mathrm{~m} / \mathrm{min}$

\begin{tabular}{|c|c|c|c|}
\hline Current (A) & \multicolumn{3}{|c|}{ Welding speed:1.6 m/min, Inter-wire distance: $12 \mathrm{~mm}$} \\
\hline $\begin{array}{c}\text { (a) } \\
\text { Leading: } 350\end{array}$ \\
Trailing: 140
\end{tabular}

Fig. 6 High-speed camera images for different leading currents

대적으로 작게 발생한다.

\section{3 후행 전류의 영향}

선행 전류를 250 A로 고정하고 후행 전류를 100 $300 \mathrm{~A}$ 로 가변하면서 용접을 수행하고 후행전류의 영향 을 검토하였다. Fig. 7의 비드 외관에서 전류가 가장 낮은 $100 \mathrm{~A}$ 일 때 스패터가 가장 적게 부탁되어 있음을 알 수 있다. 앞 절에서와 유사하게 후행 전류가 낮을 경우 전자기력이 작아 아크 간섭이 적게 발생하고 후행 전류값에 따라 선행 전극에서의 용적이행모드가 바뀌기 때문이다.

Fig. 8의 고속촬영 결과에서와 같이 후행 전류가 $100 \mathrm{~A}$ 일 때는 선행 전극에서 프로젝티드 이행이 관찰되며, $200 \mathrm{~A}$ 에서는 프로젝티드와 스트리밍이 번갈아 관찰된다. 또 한 $300 \mathrm{~A}$ 의 경우에는 스트리밍 이행이 주로 관찰되는 데, 즉 후행 전류에 의한 입열이 선행 전극에서의 용적 이행에 영향을 주고 있음을 확인할 수 있다. 본 실험에 서도 스트리밍 이행이 발생하는 경우에는 스패터가 많 이 발생하는 것이 확인되었다.

후행 전류가 $300 \mathrm{~A}$ 인 경우에는 용융량이 많아서 용
융풀 중앙부가 높아지는 현상이 발견되고 높은 용융풀 의 높이는 순간 단락을 쉽게 발생시키므로 스패터 발생 의 다른 원인이 되기도 한다.

\section{4. 결 론}

본 연구에서는 정전압 모드 $\mathrm{DC}$ 용접과 $\mathrm{AC}$ 펄스용접 을 비동기 탄뎀화하여 GMA용접을 수행하고 스패터 발 생거동을 관찰하였다. 와이어간 거리, 선행전류, 후행전 류를 가변하면서 현상을 관찰한 결과 다음과 같은 결론 을 얻었다.

1) 스패터는 주로 선행 와이어의 용적이 용융풀로 이 행되지 못하면서 발생한다. 아크 간섭으로 인해 후행 아크방향으로 날림이 발생하거나 순간적 단락으로 인한 날림이 주된 스패터 발생 메커니즘이었다.

2) 와이어간 거리가 $8 \mathrm{~mm}$ 와 같이 짧을 경우 아크 간섭 이 심하여 스패터가 많이 발생한다. 본 실험의 범위에서 와 이어간 거리가 $12-15 \mathrm{~mm}$ 일 때 스패터가 비교적 적 게 발생하였으며, $18 \mathrm{~mm}$ 일 경우에는 불균일한 비드 가 형성된다. 


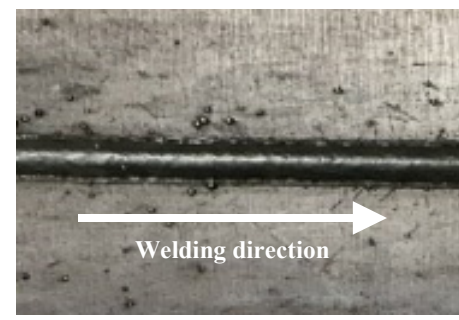

(a)

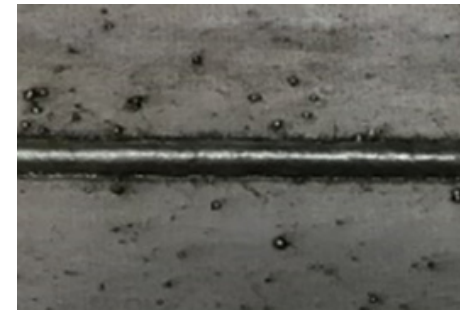

(b)

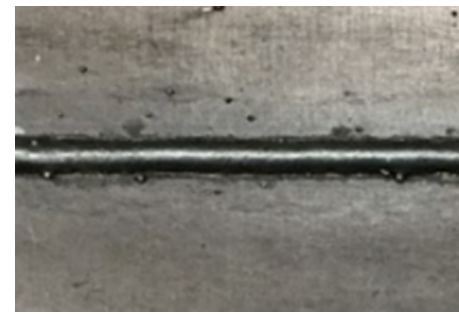

(c)

Fig. 7 Comparison of bead appearance according to the trailing current: (a) 100 A; (b) 200 A; (c) 300 A. Specimens were fabricated under inter-wire distance of $12 \mathrm{~mm}$ and welding speed of $1.6 \mathrm{~m} / \mathrm{min}$

\begin{tabular}{|l|l|l|l|l|}
\hline $\begin{array}{c}\text { Trailing } \\
\text { current (A) }\end{array}$ & \multicolumn{3}{|c|}{ Leading current: $250 \mathrm{~A}$, Welding speed:1.6 m/min, Inter-wire distance: $12 \mathrm{~mm}$} \\
\hline (b) 200 & (c) 300
\end{tabular}

Fig. 8 High-speed camera images for different trailing currents

3) 선행 전류와 후행전류값이 큰 경우 아크간의 간섭 이 커지고, 선행 전극에서의 용적이행이 프로젝티드 이 행에서 스트리밍 이행으로 변하면서 스패터 발생이 증 가한다. 후행 전류값을 높이는 경우에도 입열로 인하여 선행 전극에서의 용적이행에 영향을 줌을 확인하였다.

ORCID: Sanghoon Kang: http://orcid.org/0000-0002-2566-4570 ORCID: Hee-seon Bang: http://orcid.org/0000-0003-4891-5712 ORCID: Cheolhee Kim: http://orcid.org/0000-0003-4127-3171

\section{References}

1. K. Michie, Twin-wire GMAW, process, characteristics and applications, Welding Journal, 78(5) (1999), 31-34

2. G. Trommer, Tandem wire process improves ship panel production, Welding Journal, 88(9) (2009), 42-45

3. K.-B. Lee, C. Kim and D.-S. Kim, High deposition rate pulse gas metal arc welding for Al 5083 thick plate, Proceedings of the Institution of Mechanical Engineers, Part B: Journal of Engineering Manufacture, 227(6) (2013), 848-854

4. J. Lee, I. Kim, J. Lee, M. Park, Y. Kim and C. Park, An Experimental Study on Optimizing for Tandem Gas Metal Arc Welding Process, Journal of Welding and Joining,
32(2) (2014), 148-154

https://doi.org/10.5781/JWJ.2014.32.2.22

5. J-H. Lee, I-S. Kim, S-M Jung, J-P Lee, Y-S Kim and M-H Park, A Experiment Study of Torch Distance on Automated Tandem GMA Welding System, Journal of Welding and Joining, 30(6) (2012), 49-55 https://doi.org/10.5781/KWJS.2012.30.6.535

6. T. Ueyama, T. Ohnawa, M. Tanaka and K. Nakata, Effects of torch configuration and welding current on weld bead formation in high speed tandem pulsed gas metal arc welding of steel sheets, Science and Technology of Welding and Joining, 10(6) (2005), 750-759 https://doi.org/10.1179/174329305X68750

7. T. Ueyama, T. Ohnawa, M. Tanaka and K. Nakata, Effect of welding current on high speed welding bead formation in tandem pulsed GMA welding process, Welding International, 20(4) (2006), 262-267

https://doi.org/10.1533/wint.2006.3576

8. T. Ueyama, T. Ohnawa, T. Uezono, M. Tanaka, M. Ushio and K. Nakata, Solution to problems of arc interruption and stable arc length control in tandem pulsed GMA welding. Study of arc stability in tandem pulsed GMA welding (Report 2), Welding International, 20(8) (2006), 602-611

https://doi.org/10.1533/wint.2006.3627 
9. S. Tsushima and M. Kitamura, Tandem electrode AC MIG welding Development of AC MIG welding process (Report 4), Welding International, 8(8) (1994), 599-605 https://doi.org/10.1080/09507119409548657

10. H. J. Park, D. C. Kim, M. J. Kang and S. Rhee, The arc phenomenon by the characteristic of EN ratio in AC pulse GMAW, The International Journal of Advanced
Manufacturing Technology, 66(5-8) (2013), 867-875

https://doi.org/10.1007/s00170-012-4371-1

11. H.-S. Moon and R. Beattie, Development of adaptive fill control for multitorch multipass submerged arc welding, The International Journal of Advanced Manufacturing Technology, 19(12) (2002), 867-872 https://doi.org/10.1007/s001700200098 